\title{
REFLEXÕES ACERCA da globalização, do multiculturalismo e da literatura
}

José Luís Giovanoni Fornos

O presente ensaio versa sobre os efeitos da globalização capitalista e do multiculturalismo na paisagem social, ensejando novas questóes acerca da identidade nacional. Em primeiro lugar, nota-se que o domínio do capital global que se alastra, simbólica e materialmente, por todos os campos da atividade humana, atingindo, de maneira veloz, distantes regiốes do planeta, surpreende a ansiedade epistêmica de pensadores/escritores conscientes da complexidade que cerca a estrutura social. Hoje, as observaçóes de Adorno de que toda matéria - espiritual ou não - torna-se mercadoria, sendo avaliada conforme poder de compra e venda, ainda prevalecem.

Em um universo assinalado pelo pragmatismo econômico, pela assimetria do espaço social e cultural, pelo ceticismo político, parece inoperante referir-seà categoria utopia. Em contrapartida à baixa rentabilidade ideológica do pensamento utópico, Fredric Jameson (1997), ao discorrer sobre tal categoria, desafia a capacidade imaginativa, questionandose: como "seriam as relaçóes humanas sem a mercantilização?" De que maneira o mundo organizar-se-ia "sem a publicidade" e sem os "corpos estranhos dos negócios e do lucro", e como seria representado pelas narrativas?” (1997, p. 84) Para Jameson,

o valor epistemológico da utopia está nas paredes que ela nos permite perceber em torno das nossas mentes, nos limites invisíveis que nos permite detectar, por mera induçáo, no atoleiro das nossas imaginações, no modo de produção, a lama da época presente que se 
gruda nos sapatos da Utopia alada, imaginando que isso é a própria força da gravidade. (1997, p. 85)

O cotidiano, sob o efeito da escalada financeira e tecnológica, despreza o valor da utopia, que, reduzido à ideia da impossibilidade efetiva, é dominado por paisagens urbanas que condicionam a imaginação de sociedades alternativas. Para Jameson, as dificuldades em imaginar a constituição de um mundo para além da "estandardização global" capitalista são indícios e traços da própria "estandardização" que afeta o ser e a realidade.

A utopia, espécie de fantasmagoria que ronda toda a ordem social vigente, rompe com o mito de uma sociedade perfeita e acabada. A utopia, aqui, corresponde ao sonho nietzschiano do andarilho que, sob a liberdade da razão, não se dirige a uma meta final, já que esta não existe, o que o leva a prosseguir a caminhada sempre. A vocação negativa da utopia - sua permanente não realização - possibilita o aperfeiçoamento contínuo das sociedades, ainda que estas estejam, por vezes, afetadas por uma baixa densidade de esperança.

A expansão vertiginosa em escala global dos mecanismos de produção, distribuição e consumo, proporcionados pela intervenção técnica e política, ao mesmo tempo em que condiciona açóes, fomenta novos agentes coletivos que, coagidos pelo reordenamento econômico, transformam-se em figuras singulares dos espaços urbanos. A chamada globalização, paradoxalmente, acaba por desencadear "novos" sujeitos em defesa de suas especificidades, somando-se à formação de hibridismos identitários que, por seu turno, reforçam sentimentos de pertença local, regional e nacional.

A globalização gera situaçóes de separação e segregação. Expostas à extraterritorialidade do capital global, as sociedades enfrentam a violência, pobreza, desemprego e conflitos étnico-raciais mesclados a fortalezas privadas que pretendem a preservação e garantia do consumo e da diversão. No romance $O$ esplendor de Portugal, António Lobo Antunes retrata a situação dos imigrantes das ex-colônias portuguesas na periferia de Lisboa:

O bairro da lata amotinava-se em peso contra o dono da taberna numa guincharia de crianças e cáes, janelas acesas, postigos a baterem, correrias, um bairro com vivendas de argamassa e tijolo pelo meio, varandas decoradas por cacos de garrafa, azulejos furtados e vidrinhos de cor, automóveis que afocinhavam nos taludes, hortas de alecrim, mulas ciganas, o barracão da igreja evangélica com um letreiro que dizia Cristo Espera-te.

Se eu saía à rua a atormentar os vendedores ambulantes e os rafeiros vadios, quem me despejasse regadores de água só por puxar a roupa dos estendais ou desatarrachar as placas das campainhas com uma chave de parafuso ótima, os cretinos dos operários que 
pintavam a frontaria do União juravam matar-me se mexesse nas brochas ou lhes tirasse as escadas, aqui Damaia, ao menos, os caboverdianos do bairro da lata de fita vermelha no pulso e nos gorros marroquinos, morando num terreno baldio de canaviais e carcaças de automóvel com seu bêbedo a refogar nos estofos. (ANTUNES, 1997, p. 161)

Se a globalização mutila ou destrói formas culturais, homogeneizando práticas e recepçôes em vários lugares, também produz heterogeneidades, diversidades e diferenças. Para o sociólogo Nestor García Canclini (1997):

Problemas comuns como a poluição e o trânsito, as interaçóes com o mercado nacional e internacional, obrigam a transcender o local se quisermos entender o que ocorre em uma megalópole. Além da cidade histórica e da cidade industrial, existe a cidade globalizada, que se conecta com as redes mundiais da economia, finanças e comunicações. Até pouco tempo atrás as teorias da urbanização caracterizavam as cidades segundo diferenças notórias em relação ao campo, e pela transferência da força de trabalho de atividades agrícolas para as secundárias ou terciárias. Os estudos urbanos reconhecem como agente econômico mais dinâmico não a industrialização, mas os processos informacionais e financeiros. Esta mudança está provocando uma reconceitualização das funções das grandes cidades. (CANCLINI, 1997, p. 85-86)

A padronização crescente do "econômico-cultural” em nível mundial revela-se um movimento contraditório, pois aguça tensôes, produzindo reações ao mal-estar provocado pela rápida liquidez que atinge sujeitos e objetos. Resultado de um novo surto de universalização do capitalismo como modo de produção e processo civilizatório, a globalização soa com integração e homogeneização, da mesma forma que com diferenciação e fragmentação. Para Octavio Ianni (2001), a "sociedade global está tecida por relaçóes, processos e estruturas de dominação e apropriação, integração e antagonismo, soberania e hegemonia. Trata-se de uma configuração histórica problemática, atravessada pelo desenvolvimento desigual, combinado, contraditório" (p. 30)

No romance Nem só, mas também o escritor português Augusto Abelaira escreve:

- Os governantes de direita e de esquerda fazem mais ou menos as mesmas políticas, aparentemente nem podem fazer outras. Entalados pela globalização. Que concluir? Lembras-te dos tempos quando esperávamos essa crise, a crise fatal do capitalismo? O mundo do salve-se quem puder, o mercado é a lei divina, mesmo quando empurra um terço da população mundial para a miséria. (ABELAIRA, 2004, p. 134)

A figura do "capital global" consolida-se como força-motriz dominante, entranhando-se e deslocando-se irregularmente em múltiplas extensões espaciais, validando a avaliação de Marx e Engels, no Manifesto Comunista: 
Impelida pela necessidade de mercados sempre novos, a burguesia invade todo o globo terrestre. Necessita estabelecer-se em toda a parte. Pela exploração do mercado mundial, a burguesia imprime um caráter cosmopolita à produçáo e ao consumo em todos os países. Para desespero dos reacionários, ela roubou da indústria sua base nacional. As velhas indústrias nacionais foram destruídas e continuam a ser destruídas diariamente. São suplantadas por novas indústrias, cuja introdução se torna uma questão vital para todas as naçôes civilizadas — indústrias que já não empregam matérias-primas nacionais, mas sim matérias -primas vindas das regiôes mais distantes, e cujos produtos se consomem não somente no próprio país mas em todas as partes do mundo. Ao invés das antigas necessidades, satisfeitas pelos produtos nacionais, surgem novas demandas, que reclamam para sua satisfação os produtos das regióes mais longínquas e de climas os mais diversos. No lugar do antigo isolamento de regióes e naçôes autossuficientes, desenvolvem-se um intercâmbio universal e uma universal interdependência das naçôes. E isto se refere tanto à produção material como à produção intelectual. As criaçóes intelectuais de uma nação tornam-se patrimônio comum. (MARX e ENGELS, 1998, p. 43)

Ainda que mencione cinco níveis distintos - o tecnológico, o político, o cultural, o econômico e o social — ao fenômeno da globalização, Fredric Jameson (2001) alerta para sua dimensão econômica que parece sempre expandir-se para os demais níveis. A dimensão econômica controla as novas tecnologias, reforça os interesses geopolíticos, dissolvendo o cultural no econômico e o econômico no cultural. Dessa forma, a produção de mercadorias é "agora um fenômeno cultural, no qual se compram os produtos tanto por sua imagem quanto por seu uso imediato” (p. 22), surgindo, assim, toda uma indústria para planejamento da imagem das mercadorias e estratégias de venda. Para Jameson, a "propaganda torna-se uma mediação fundamental entre cultura e economia, e se inclui certamente entre as inúmeras formas da produção estética”. (p. 22)

Pierre Bourdieu (1998) identifica a globalização como um mito poderoso, intencionalmente composto para combater conquistas sociais históricas dos trabalhadores. A globalização "ratifica e glorifica o reino que se chama mercados financeiros, estimulando a volta a uma "espécie de capitalismo radical sem freio, cuja única lei é a do lucro máximo". (p. 50) Para o sociólogo francês, tal modelo é "levado ao limite de sua eficiência econômica pela introdução de formas modernas de dominação, como técnicas de manipulação, como a pesquisa de mercado, o marketing, a publicidade comercial”. (p. 50)

O estágio atual do capitalismo ocidental compromete o pluralismo teórico e metodológico.Ardilosas armadilhas promovidas pela estrutura econômico-comunicacional expulsam a reflexão teórica séria, relegando o estudioso/escritor a espaços restritos de atuação. Para Bourdieu, a "autonomia dos universos de produção cultural em relação ao mercado, que não havia cessado de crescer graças às lutas e os sacrifícios dos escritores, artistas e intelectuais, está cada vez mais ameaçada”. (p. 52) No contexto histórico atual, 
o reino do 'comércio' e do 'comercial' se impóe cada dia mais à literatura, notadamente por meio da concentração dos canais de comunicação, cada vez mais diretamente submetidos às exigências do lucro imediato; a crítica literária e artística, entregue aos acólitos mais oportunistas dos editores - ou de seus cúmplices, com as trocas de favores - , e principalmente ao cinema; sem falar das ciências sociais, condenadas a submeter-se às encomendas diretamente interessadas das burocracias de empresas ou de Estado, ou a morrer pela censura dos poderes ou do dinheiro. (BOURDIEU, 1998, p. 52-53)

A sociedade de mercado atrofia as excentricidades e idiossincrasias do discurso artístico-transgressor. Enquanto isso a realidade, revivida em fragmentos de imagens, estampa enormes contingentes humanos anônimos à procura de referenciais que lhes permitam reconhecimento, segurança e estabilidade. Envolvidos por um sistema que se organiza na dissolução ininterrupta de formas e conteúdos, homens e mulheres ainda sonham com condiçóes mínimas de existência que lhes garanta a inclusão social.

A inclusão, porém, esbarra com o tempo presente cuja característica está no não fornecimento de lugares para a reacomodação social. De acordo com Zygmunt Bauman (2001), "os lugares que podem ser postulados e perseguidos mostram-se frágeis e frequentemente desaparecem antes que o trabalho de reacomodação seja completado". (p. 42) Para o sociólogo polonês, o que existe são "cadeiras musicais" de diversos tamanhos e estilos, em números e posiçóes cambiantes, que fazem com que pessoas estejam em movimento permanente, não prometendo nem a realização, nem o descanso.

Açóes emblemáticas no seio da intelectualidade e do movimento social refletem tal dinâmica. Na década de 1990, Bourdieu, contrariando certas práticas acadêmicas, dirige-se às ruas de Paris, conclamando a populaçáo a rebelar-se contra a reforma das leis trabalhistas proposta pelo governo francês. Em diferentes países, há protestos crescentes contra o modelo societário vigente. No Brasil, a luta por uma reforma agrária e urbana tem concentrado atençóes. A complexidade histórica, característica de todo modelo societário humano, parece naufragar frente aos acontecimentos embriagantes que dominam o espetáculo do mundo, justificando, em muitos momentos, as palavras do Manifesto Comunista:

A burguesia não pode existir sem revolucionar incessantemente os instrumentos de produção; por conseguinte, as relações de produção e, com isso, todas as relaçôes. Essa subversão contínua da produção, esse abalo constante de todo o sistema social, essa agitação permanente e essa falta de segurança distinguem a época burguesa de todas as precedentes. Dissolvem-se todas as relaçôes sociais antigas e cristalizadas, com seu cortejo de concepçôes e de ideias secularmente veneradas; as relaçóes que as substituem tornam-se antiquadas antes de se consolidarem. Tudo o que era sólido e estável se desmancha no ar, tudo o que 
era sagrado é profanado e os homens são obrigados finalmente a encarar sem ilusões a sua posição social e as suas relaçôes com outros homens. (MARX e ENGELS, 1998, p. 43)

A ênfase "positiva" dada por Marx e Engels às transformações provocadas pelo capitalismo, que servem de suporte estrutural para formação do modo comunista de produção, estende-se igualmente aos intercâmbios espaciais e culturais. Segundo Marx e Engels (1998):

A burguesia submeteu o campo à cidade. Criou grandes centros urbanos; aumentou prodigiosamente a população das cidades em relação à dos campos e, com isso, arrancou uma grande parte da população do embrutecimento da vida rural. Do mesmo modo que subordinou o campo à cidade, os povos bárbaros ou semibárbaros aos países civilizados, subordinou os povos camponeses aos povos burgueses, o Oriente ao Ocidente. (p. 44)

Tal juízo encontra-se comprometido. Embora as avaliaçôes estejam corretas, não impediram a configuração de um dinamismo histórico e social parcialmente diferenciado daquele preconizado. O destaque à lógica do progresso industrial - estímulo à luta de classes - minimiza ou desconsidera a questão ambiental e as raízes culturais. Também com a implosão do proletariado como classe universal revolucionária, parte das teses de Marx fragiliza-se, indeterminando "epistemicamente", para muitos teóricos, as características do sujeito histórico revolucionário.

Ainda que a luta de classes tenha validade para se compreender as relaçóes sociais, o sujeito universal é submetido a outras "determinidades", que vão da escolha sexual, raça, gênero, religião, etnia, idade, família à importância do território nacional e local na formação da identidade. O sujeito histórico é repensado à luz da multiplicidade cultural e social, traduzida na vivência de hábitos e ideias e na mobilidade das relaçôes espaço-temporais.

Agrega-se ao pluralismo a presença-ausência do passado na constituição da imaginaçáo histórica, vestígio que Marx, embora consciente ${ }^{1}$, reprime à medida que deseja a transformação de um modo de produção em outro. Atento à dinâmica progressiva da história e com os olhos voltados para a revolução, Marx recalca a questão da herança e memória culturais na formação de cada indivíduo e sociedade. Em $O 18$ Brumário, defende a ruptura com o passado em nome da revolução, utilizando-se de metáforas que apontam para essa mudança:

Assim, Lutero adotou a máscara do apóstolo Paulo, a Revolução de 1789-1814 vestiu-se alternadamente como república romana e como império romano, e a Revoluçáo de 1848 não soube fazer nada melhor do que parodiar ora 1789 , ora a tradição revolucionária de 1793-1795. De maneira idêntica, o principiante que aprende um novo idioma, traduz 
sempre as palavras deste idioma para sua língua natal; mas só quando puder manejá-lo sem apelar para o passado e esquecer sua própria língua no emprego da nova, terá assimilado o espírito desta última e poderá produzir livremente nela. (MARX, 1997, p. 21-22)

A luta política pela valorização das diferenças deve fazer parte de qualquer projeto artístico, contrabalançando as ameaças de opressão ligadas à própria ideia de uma história universal, realizada a partir da hegemonia de uma sociedade particular ou um pequeno grupo de sociedades dominantes. O combate à discriminação identitária e sua emancipação é correlativo à busca de um novo ordenamento sociocultural. Nesse sentido, Ricoeur (1991) chama a atenção para o fato de que "os direitos à diferença" não mereceriam o "nome de direitos sem a realização simultânea de um Estado de direito" (p. 372) em que os indivíduos e as coletividades não-estatais permanecessem como os últimos sujeitos de direito. As chamadas micropolíticas ${ }^{2}$ que problematizam as açóes hegemônicas do poder possuem um papel significativo na transformação das relaçóes sociais, devendo estar conscientes de que a garantia de uma identidade constitui-se, em última instância, na luta pela reorganização geral do sistema. As políticas de identidade possuem um papel significativo na transformação das relaçóes entre Estado e sociedade. Elas devem buscar equilíbrio dialético entre o social e o cultural. Boaventura de Sousa Santos (2003) denomina tal direcionamento de "hermenêutica diatópica", que pressupóe a aceitação do seguinte imperativo intercultural: "temos o direito a ser iguais quando a diferença nos inferioriza; temos o direito a ser diferentes quando a igualdade nos descaracteriza” (p. 458). Nesse sentido, é preciso pensar a articulação entre a luta pela distribuição e a luta pelo reconhecimento no quadro da globalização capitalista hegemônica.

As manifestações a favor da diferença transformam-se em um campo privilegiado de investimentos. Stuart Hall (2003) aposta numa política da diferença, reconhecendo, todavia, as limitações e os riscos de cooptação. Escreve:

As estratégias culturais capazes de fazer a diferença são o que me interessa - aquelas capazes de efetuar diferenças e de deslocar as disposiçôes do poder. Reconheço que os espaços conquistados para a diferença são poucos e dispersos, e cuidadosamente policiados e regulados. Acredito que sejam limitados. Sei que eles são absurdamente subfinanciados, que existe sempre um preço de cooptaçáo a ser pago quando o lado cortante da diferença e da transgressão perde o fio na espetacularização. Eu sei que o que substitui a invisibilidade é uma espécie de visibilidade cuidadosamente regulada e segregada. Mas simplesmente menosprezá-la, chamando-a de o mesmo, não adianta. (HALL, 2003, p. 339)

Para alguns, trata-se de um discurso cuja agressividade é passível de controle. Incorporado com facilidade, funciona como tema subversivo sem pôr em risco o modo 
de produção. Nesse caso, a celebração da diferença e da diferenciação funciona como conteúdo cultural dos meios de comunicação de massa hegemônicos que projetam todas as culturas do mundo num contato simpático umas com as outras numa espécie de imenso pluralismo de que é muito difícil não gostar. Ao alçar a valorizaçẫo das diferenças como única razão para emancipação dos sujeitos, arrefece-se o questionamento da estrutura social em sua totalidade, secundarizando situaçóes como a produção do desemprego, expressão da exclusão no modelo econômico atual. A passagem do desemprego enquanto tema social essencial para uma questáo exclusivamente individual, fruto da fatalidade econômica, escamoteia o próprio funcionamento do modelo em vigência, afastando a possibilidade de entendê-lo em sua essência.

Reflexo da reorganizaçáo do modelo produtivo, os sujeitos sem-trabalho referendam, por linhas tortas e negativas, a posição de Marx, ao anunciar que, sem as mazelas da divisão do trabalho, os homens superariam a praxis reificada e ocupariam tarefas múltiplas conforme o interesse e o prazer $^{3}$. Coagidos pela necessidade, os sujeitos sem-trabalho, quando aceitos no mercado, acatam atividades precárias, preenchidas em posiçôes temporárias e interinas. A ameaça constante do desemprego sujeita o indivíduo à precariedade dos contratos de trabalho, afetando profundamente qualquer homem ou mulher exposto a seus efeitos. Para Bourdieu (1998), ao tornar o futuro incerto, a precariedade impede qualquer "antecipação racional e, especialmente, esse mínimo de crença e de esperança no futuro", necessária "para se revoltar, sobretudo coletivamente, contra o presente, mesmo o mais intolerável". (p. 51) A insegurança objetiva do desemprego funda uma insegurança subjetiva generalizada que afeta os trabalhadores e até aqueles que não estão ou ainda não foram diretamente afetados.

Ainda que o capitalismo, engendrado cultural e materialmente na apologia da liberdade individual, tenha revelado em diferentes etapas de sua história dificuldades que o expóe a riscos, a passagem do "reino da necessidade" para o "reino da liberdade", pretendida por Marx, continua em compasso de espera. Assim, o desejo de redenção social humana mais equânime, construída a partir da estruturação de um modo de produção planejado e decidido coletivamente, aguarda sua afirmação histórica.

$\mathrm{O}$ mito da liberdade individual contrapóe-se ao mito coletivista. A história do século XX encena-os em contraste dramaticamente, limitando tanto aqueles que vivem sob a chamada economia de mercado "livre" quanto aos que viveram as economias planificadas dos países do leste europeu. Os dois modelos balizam sentimentos e açóes dos sujeitos, estimulando imagens representativas da condição do eu. A derrota do modelo soviético fortalece provisoriamente o modo de produçáo capitalista que, embora hegemônico, expôe situaçốes de fragilidade, pondo em dúvida seu projeto. 
Para Jameson (1997), os dois modelos societários afetam a imaginação dos sujeitos, engendrando fantasias utópicas conforme as experiências vividas:

Assim é que uma população sofrendo os excessos do individualismo e uma anomia da qual nem sempre se dá conta será suscetível à influência de visóes articuladas de solidariedade e vida coletiva. O contrário, no entanto, também se sustenta claramente, de forma que pessoas que se "ajuntaram" por períodos indeterminados, tais como as várias populaçôes da antiga Uniáo Soviética, devido a toda uma cadeia de situaçôes catastróficas nas quais se encontraram, podem tanto desenvolver um horror da união em situaçóes cotidianas e um almejo à privacidade individual e à vida privada "burguesa", quanto adquirir categorias e hábitos de experiência coletiva desconhecidos e incompreensíveis para o Ocidente. (JAMESON, 1997, p. 110)

A dialética individualidade/coletividade deve ser repensada à luz dos acontecimentos atuais em que a emergência de hibridismos socioculturais aponta para a necessidade de políticas identitárias. Se o descrédito do marxismo como filosofia da história pautara as discussóes recentes, contaminadas pela derrota do chamado socialismo real soviético, a fragilidade utópica do mundo capitalista globalizado devolve às teorias marxistas e neomarxistas, em suas vertentes diversas, potencialidades críticas.

Em virtude dos postulados teóricos que balizam a reflexão política de esquerda, o capitalismo globalizado é posto em suposta revisão por seus próprios ideólogos que temem repercussóes negativas com o crescimento de protestos em diferentes partes do planeta. O caráter autofágico do capital significa sua desmistificação como utopia planetária. A fabricação do descontrole é a única racionalidade que parece demarcar o funcionamento capitalista a fim de continuar produzindo riqueza material e espiritual para poucos. Nesse sentido, sua configuração permite que as diferentes "versōes" dos escritos de Marx sejam atualizadas, sem que sejam postas, por completo, no anonimato da história.

Ainda que a teoria constitua-se em referencial oportuno, a produção artística, em especial a literatura, engendra iguais possibilidades de análise, tecendo, através de suas estratégias específicas, ações humanas regidas na totalidade dos eventos. A representação da produçáo literária consiste na revelação do homem por inteiro, produto e produtor do espaço. Nessa perspectiva, a ficção narrativa e a poesia devem ser tomadas como estruturas artísticas importantes, e preparadas para a compreensão da sociedade em suas múltiplas dimensões.

\section{$\operatorname{sos}$}




\section{NOTAS}

1 Marx escreve em $O 18$ do Brumário: "os homens fazem a sua própria história, mas nas circunstâncias encontradas, dadas, transmitidas". (p. 4)

2 De acordo com Félix Guattari, uma "micropolítica do desejo não mais se proporia a representar as massas e a interpretar suas lutas. Ela investiria, ao contrário, numa multiplicidade de objetivos ao alcance imediato dos mais diversos conjuntos sociais, implicando "um questionamento radical dos movimentos de massa decididos centralizadamente e que fazem funcionar indivíduos serializados". (In: GUATTARI, F. Revolução molecular: pulsaçôes políticas do desejo. São Paulo: Brasiliense, 1981, p. 176-177.)

3 Marx chama a atençáo para o fato de que "a partir do instante em que o trabalho começa a ser dividido, cada um tem uma esfera de atividade exclusiva e determinada, que lhe é imposta e da qual ele pode fugir; ele é caçador, pescador, pastor ou crítico, e deverá permanecer assim se não quiser perder seus meios de sobrevivência; ao passo que, na sociedade comunista, em que cada um náo tem uma esfera de atividade exclusiva, mas pode se aperfeiçoar no ramo que lhe agradar, a sociedade regulamenta a produção geral, o que cria para mim a possibilidade de hoje fazer uma coisa, amanhã outra, caçar de manhă, pescar na parte da tarde, cuidar do gado ao anoitecer, fazer crítica após as refeições, a meu bel-prazer, sem nunca me tornar caçador, pescador ou crítico". (In: ENGELS, F. e MARX, K. A ideologia alemã. São Paulo: Martins Fontes, 1998, p. 28)

\section{REFERÊNCIAS}

ABELAIRA, Augusto. Nem só, mas também. Lisboa: Presença, 1996.

ADORNO, T. W. e HORKEIMER. Dialética do esclarecimento. Rio de Janeiro: Jorge Zahar, 1986.

ANTUNES, António Lobo. Esplendor de Portugal. Lisboa: Dom Quixote, 1988.

BAUMAN, Zygmunt. Modernidade líquida. Rio de Janeiro: Jorge Zahar, 2001.

BOURDIEU, Pierre. Contrafogos: táticas para enfrentar a invasão neoliberal. Rio de Janeiro: Jorge Zahar, 1998.

CANCLINI, Néstor Gárcia. Consumidores cidadãos. Rio de Janeiro: Ufrj, 1997.

HALL, Stuart. Da diáspora: identidades e mediações culturais. Belo Horizonte: UFMG, 2003.

GUATTARI, Félix. Revolução molecular: pulsaçōes políticas do desejo. São Paulo: Brasiliense, 1981.

IANNI, Otávio. A era do globalismo. Rio de Janeiro: Civilização Brasileira, 2001.

JAMESON, Fredric. A cultura do dinheiro. Petrópolis; RJ: Vozes, $2001 \mathrm{a}$.

JAMESON, Fredric. As sementes do tempo. São Paulo: Ática, 1997b.

MARX, K. e ENGELS, F. Manifesto comunista. São Paulo: Boitempo, 1998.

MARX, Karl. O 18 do Brumário e cartas a Kulgelmann. Rio de Janeiro: Paz e Terra, 1997.

NIETZSCHE, F. Humano, demasiado humano. São Paulo: Companhia das Letras, 2000.

RICOEUR, Paul. Ideologia e utopia. Lisboa: Edições 70, 1991a.

RICOEUR, Paul. Tempo e narrativa. V. III. Campinas; SP: Papirus, $1997 \mathrm{~b}$.

RICOEUR, Paul. Tempo e narrativa. V.I. Campinas; SP: Papirus, $1994 \mathrm{c}$.

SANTOS, Boaventura de Sousa. Pela mão de Alice: o social e o político na pós-modernidade. Sáo Paulo: Cortez, 1995. 


\section{Resumo}

O presente ensaio discute as relaçóes entre a economia capitalista global e o universo social assinalado pelas trocas materiais e pelos hibridismos identitários e culturais. Para tal discussão, são retomadas passagens do Manifesto Comunista, de Marx e Engels, mostrando a validade das observaçôes feitas ainda hoje. As posiçôes críticas à globalizaçâo igualmente são expostas pelos autores Fredric Jameson e Pierre Bourdieu, que defendem a categoria da utopia nesse cenário. Quanto à questão multicultural, são trazidas as reflexôes de Stuart Hall e Boaventura de Sousa Santos, ilustradas com trechos de romances de dois escritores portugueses: António Lobo Antunes e Augusto Abelaira.

Palavras-chave: Globalização, Multiculturalismo, Sociedade, Literatura, António Lobo Antunes, Augusto Abelaira.

\section{Abstract}

This paper approaches the global capitalistic economy in relation to the societal relationships characterized by the exchanges of material goods and the identity and cultural hybridism. To approach that topic, excerpts from the Communist Manifesto by Marx and Engels are reviewed to show the validity of those observations even in today's world. The criticism about globalization is also exposed by the authors Fredric Jameson and Pierre Bourdieu, who indorse the category of utopia in this scenery. Concerning the multiculturalism issue, this paper shows reflections by Stuart Hall and Boaventura de Souza Santos, which are based on excerpts taken from novels by two Portuguese writers: António Lobo Antunes e Augusto Abelaira.

Key words: Globalization, Multiculturalism, Society, Literature, António Lobo Antunes, Augusto Abelaira.

José Luís Giovanoni Fornos é professor adjunto de Literatura Portuguesa da Universidade Federal do Rio Grande (FURG) e professor do Programa de Pós-Graduação em História da Literatura do Instituto de Letras e Artes da mesma universidade. Doutor em Teoria da Literatura pela PUC-RS. É inscrito no GT de Estudos Comparados de Literaturas de Língua Portuguesa. Realiza pesquisas acerca de autores contemporâneos de língua portuguesa com ênfase em Portugal e África, considerando as relaçôes entre sociedade e cultura. 